\title{
AVALIAÇÃO E MONITORAMENTO DE PROCESSOS DE PRODUÇÃO UTILIZANDO RECURSO DA GESTÃO À VISTA EM UMA GRANDE INDÚSTRIA DO SETOR TÊXTIL NO ESTADO DO RIO GRANDE DO NORTE.
}

\section{Ricardo Pires de Souza}

Mestre em Engenharia de Produção pela Universidade Federal do Rio Grande do Norte - UFRN Professor da Universidade Federal do Rio Grande do Norte - UFRN ripiso@gmail.com (Brasil)

\section{Hélio Roberto Hékis}

Doutor em Engenharia de Produção pela Universidade Federal de Santa Catarina - UFSC hekis1963@gmail.com (Brasil)

\section{Rutênio de Medeiros Ribeiro}

rutenio_ribeiro@msn.com (Brasil)

\section{Ricardo Alexsandro de Medeiros Valentim}

Doutor em Engenharia Elétrica pela Universidade Federal do Rio Grande do Norte - UFRN Professor da Universidade Federal do Rio Grande do Norte - UFRN

ricardo.valentim@ufrnet.br (Brasil)

\section{RESUMO}

Competição industrial exige cada vez mais das companhias que necessitam buscar novas alternativas, a fim de se manterem competitivas no mercado. As ferramentas de gestão à vista auxiliam na comunicação, proporcionando agilidade na resolução de problemas trazendo benefícios para as companhias. Assim o presente estudo tem como objetivo demonstrar a implantação de modo dinâmico, padronizado e eficaz de ferramentas de Gestão à Vista com o intuito de aprimorar a eficácia da propagação da informação em uma da planta das maiores indústrias brasileira do setor têxtil, almejando tornar a empresa mais competitiva no mercado global. A presente pesquisa será do tipo, exploratória, descritiva e avaliativa, tendo como o modo de investigação a pesquisa-ação. Os dados foram coletados através de entrevistas não estruturadas, análise documental e observação. Após quatro meses da implementação das ferramentas de gestão a vista, percebeu-se redução de $40 \%$ na quantidade de número de rondas efetuadas pelos supervisores nas linhas de produção, redução de $61 \%$ no tempo de máquina paradas e acréscimo de $68 \%$ na produtividade diária. Outro resultado importante no estudo ficou evidenciado na melhora da comunicação entre os colaboradores, menos falha no processo e melhor acompanhamento da produção por parte da gerência.

Palavras Chaves: Gestão à Vista, Produtividade, Pesquisa-ação. 


\section{INTRODUÇÃO}

A Gestão à Vista é um assunto que vem sendo muito discutido, nesta última década, por especialistas da área e líderes das organizações em face das incertezas ambientais, organizacionais, gerenciais e operacionais. O ambiente organizacional altera-se de modo muito rápido, trazendo uma preocupação constante aos seus líderes, os quais buscam novas estratégicas para serem competitivos (RANGEL et al., 2010), pois os consumidores estão exigindo melhor qualidade do produto e do serviço a preços cada vez mais baixo (PINTO et al., 2006).

Diante da intensificação da concorrência internacional, as empresas têm perseguido diferentes estratégias para sobreviverem. Nesse sentido, Slack (1993), argumenta que para as empresas adquirirem competitividade, devem possuir: qualidade, prazos reduzidos de entrega, confiabilidade, flexibilidade para alterar o produto ou o processo de fabricação e custos reduzidos.

As companhias com alta capacidade competitiva têm adotado soluções que honram a abordagem da administração participativa, que podem aumentar a criatividade, capacidade de aprendizagem e inovação, resultando em uma melhor tomada de decisão (PARDO-DEL-VAL et al., 2012).

Aqueles que efetuam o trabalho segundo Bravo (2003), obtém mais conhecimento a respeito dele do que qualquer outra pessoa. Eles podem não saber como analisar ou traduzir seu conhecimento, mas sabem o que funciona e o que não funciona.

Logo fica claro que o aprimoramento de qualquer função ou tarefa começa pelas pessoas que, de fato, executam o trabalho, e entendendo as relações interpessoais que existem nesse ambiente e como funciona a relação hierárquica.

Assim, o presente estudo aborda a implantação de recursos da gestão a vista com o intuito de aprimorar a eficácia da propagação da informação em uma planta de uma das maiores indústrias brasileira do setor têxtil, almejando tornar a empresa mais competitiva no mercado global.

O presente artigo esta dividido em seis seções. Essa seção introdutória é seguida pela seção 2, que traz um resumo teórico dos principais temas discutidos. A seção 3 apresenta os aspectos metodológicos, enquanto as seções 4 e 5 apresentam um estudo de caso em uma das maiores empresas brasileiras do setor têxtil e os resultados obtidos respectivamente. Finalmente, a seção 6 apresenta as conclusões, limitações e sugestões para estudos futuros. 


\section{REVISÃO DA LITERATURA}

Segundo Slack (2007) o Planejamento e Controle da Produção - PCP preocupa-se com operar os recursos ao nível diário de modo a fornecer bens e serviços que preencherão as exigências dos consumidores. O PCP requer a conciliação do fornecimento e da demanda em termos de volume, tempo e qualidade e para conciliar o volume e o tempo, são desempenhadas três atividades distintas, embora integradas:

\footnotetext{
$\checkmark$ Carregamento: determinação do volume com o qual uma operação produtiva pode lidar;

$\checkmark \quad$ Sequência: determinação da prioridade de tarefas a serem desempenhadas;

$\checkmark \quad$ Programação: decisão do tempo (momento) o início e o fim para cada operação.
}

Em um sistema produtivo para se alcançar metas e consolidar estratégias, é necessário formular planos, administrar recursos humanos, direcionar estes recursos acompanhando a produção, corrigindo alguns desvios que vierem a surgir (SLACK, 1993).

De acordo com Tubino (2000), o Acompanhamento e Controle da Produção, por meio da coleta e análise dos dados, busca garantir que o programa de produção emitido seja executado a contento. Quanto mais rápido os problemas forem identificados, mais efetivas serão as medidas corretivas visando ao cumprimento do programa de produção.

Em termos gerais, o mesmo autor destaca que o acompanhamento e controle da produção fornece suporte ao sistema produtivo no sentido de garantir que as atividades programadas e planejadas para o período sejam cumpridas. Seu objetivo é promover uma ligação entre o planejamento e a execução das atividades operacionais, identificando os desvios, sua magnitude e fornecendo subsídios para que os responsáveis pelas ações corretivas possam agir.

O ritmo de mudança global solicita altos níveis de capacidade de reação das organizações acompanhar e reagir a mudanças no ambiente externo (LAUDON; LAUDON, 2004). Quanto mais rápida for à identificação dos problemas, mais eficientes serão as ações do acompanhamento e controle da produção, menores serão os desvios a corrigir, gerando economia de tempo e de despesas (TUBINO, 2000).

A busca por economia de tempo reflete na redução de custos e podem ser implementadas utilizando algumas ferramentas do modelo Toyota de produção, tais como o Just-In-Time (JIT). Segundo Schonberger (1994), a implementação do JIT provoca uma redução gradual no nível de estoques, o que revela mais problemas, e força os trabalhadores a buscarem soluções mais dinâmicas, tornando a multifuncionalidade uma qualificação essencial. Algumas expressões são geralmente 
usadas para traduzir aspectos da filosofia Just-In-Time: eliminação de estoques, eliminação de desperdícios, manufatura de fluxo contínuo, esforço contínuo na resolução de problemas, melhoria contínua dos processos (ROSSETTI et al., 2008).

Um dos maiores elementos do JIT é o sistema kanban. Esse sistema que pode ser traduzido por "anotação visível”, ou sinal. é muito utilizado para apoiar a redução de custos e melhorar a comunicação (AGHAJANI et al, 2012). De modo geral, no mundo inteiro esta palavra vem sendo utilizada com o significado de cartão, pois esse sistema é reconhecido por empregar determinados cartões para avisar ou informar a necessidade de entregar e/ou produzir certa quantidade de peças, itens ou matérias-primas (FURUKAWA; HONG, 1993)

Os sistemas kanban são excelentes auxiliares na gestão de processos, pois o gerenciamento de processos busca contribuir para o bom desempenho e engrandecimento da organização proporcionando ganhos em flexibilidade, redução de custo e de tempo perdido, gerando valor para os clientes e a redução ou eliminação de perdas (CHEE, et al, 2012).

O estudo dos processos tem como objetivo relacionar as atividades para trabalhem de forma coordenada e alinhada com um fim comum, que é a satisfação do cliente. Segundo Corrêa et al. (2007), a análise para melhoria de processos é estruturada em seis passos, conforme ilustrado na Figura 1.

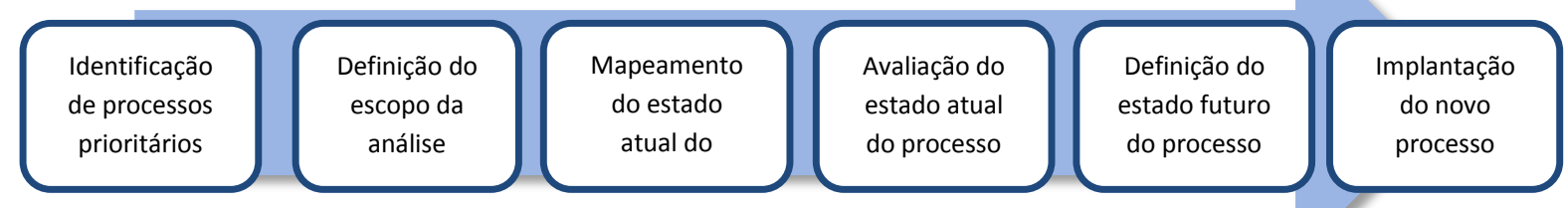

Figura 1 - Etapas da análise para melhoria de processos

Fonte: Adaptado de Corrêa et al. (2007).

A Figura 1 traduz as etapas da análise de melhorias de processos, iniciando na identificação dos processos prioritários, onde ocorrerá a busca por critérios de maior benefício potencial e maior probabilidade de sucesso. O passo seguinte irá selecionar quais as atividades que irão fazer parte do escopo de análise do projeto de melhoria. Os passos 3 e 4 buscam mapear e avaliar o estado atual do processo para se conhecer os detalhes do processo avaliado.

Os dois últimos passos estão relacionados ao planejamento do processo, os quais buscam definir o estado futuro do processo e sua implementação. 
Para um gerenciamento eficaz do processo pode-se utilizar de algumas técnicas tais como: Brainstorming, diagrama de causa e efeito, gestão a vista e para implementação de projeto o método 5W1H (SLACK, 1993).

O Brainstorming traduzido como Tempestade Cerebral é para Rodrigues (2004) uma técnica utilizada para auxiliar uma equipe a gerar/criar ideias no menor espaço de tempo possível.

A abordagem de Bateman e Snell (1998, p.103) sobre o Brainstorming fala de um ambiente de livre verbalização de ideias diante de um problema delimitado pelos gestores:

\begin{abstract}
"Quando as pessoas esgotarem suas ideias, uma longa lista de alternativas terá sido gerada. Somente então o grupo passará ao estágio de avaliação. Nesse ponto, muitas ideias diferentes podem ser consideradas, modificadas ou combinadas em uma solução sob medida criativa para o problema".
\end{abstract}

O diagrama de causa-efeito, também chamado diagrama espinha de peixe ou diagrama de Ishikawa, em homenagem ao seu desenvolvedor, foi criado para representar a relação entre um efeito e todas as possibilidades de causas, a qual pode contribuir para esse efeito. Esta técnica é muito boa para estabelecer relacionamentos entre opiniões levantadas em Brainstorming ou outra forma de levantamento de dados (SCAVARDA, 2006).

Embora seja preciso estar atento ao efeito que se deseja solucionar e a sua relação com as mais diversas causas enumeradas no Diagrama de causa e efeito, Colengui (2003) destaca que essa é uma ferramenta eficaz na determinação de causas (problemas) e percepção dos efeitos (ineficiências), destacando como ponto positivo seu alto grau de aplicabilidade no gerenciamento da qualidade.

No diagrama de causa-efeito é permitido que sejam elencadas possíveis causas de um problema (efeito) para então serem confrontadas com os dados coletados. As causas principais podem ser agrupadas sob 6 categorias conhecidas como os 6M: Mão-de-obra, Meio Ambiente, Medição, Máquinas, Método, Matéria prima (GWIAZDA, 2006), conforme visualizado na Figura 2.

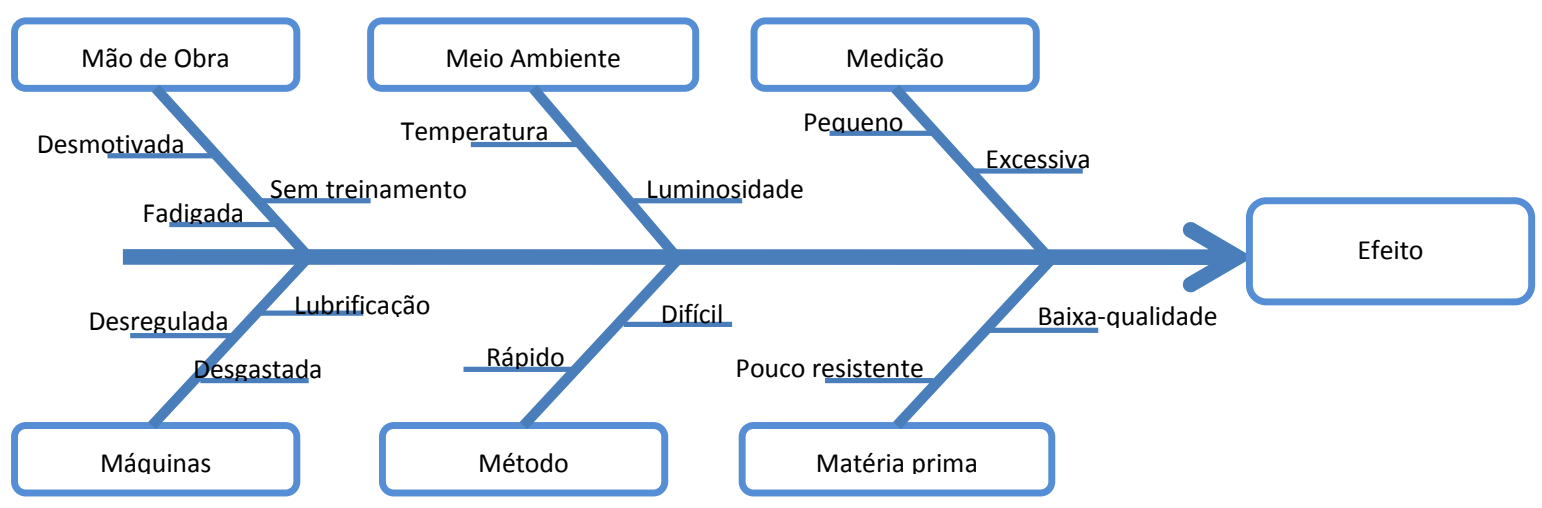

Figura 2 - Diagrama Causa-Efeito

Fonte: Adaptado de Gwiazda , 2006.

Revista de Administração e Inovação, São Paulo, v. 11, n.1, p.162-180, jan./mar. 2014. 
A Figura 2 demonstra que cada possível causa de um defeito deve ser analisado cautelosamente buscando identificar a causa de um problema, buscando solucioná-lo.

Para uma gestão de processos eficiente e eficaz se faz necessário um fluxo de informação constante e seguro (DAVENPORT; PRUSAK, 1998). Uma boa estratégia de comunicação deve ser projetada em função das pessoas que vão entender a informação: Que canais / meios de comunicação são mais convenientes? A que distância estão os indivíduos? Que jargões tal equipe utiliza? Quais são as barreiras comunicacionais existentes?

Conforme Tonkin (1998) sabe-se que as pessoas recordam de: 10\% dos que elas escutam; 25\% do que elas vêem; $50 \%$ do que elas escutam e vêem; $75 \%$ do que elas fazem e $90 \%$ do que elas escutam, vêem e fazem.

Diante deste cenário é onde surge a Gestão à Vista, bem definida, segundo Mello (1998), como forma de comunicação disponível à qualquer um que trabalha em uma dada área, para todos que estejam de passagem por esta área e para qualquer um que possa visualizá-la. Ou seja, é aquela comunicação que está disponível em uma linguagem acessível para todos aqueles que possam vê-la, trazendo uma nova luz e uma nova vida à cultura no local de trabalho, através do compartilhamento das informações.

Deste modo entende-se que Gestão à Vista em geral traz benefícios tais como: maior criatividade e aumento da inovação (KIERNAN, 1993; LAWLER, 1993; QUINN; SPREITZER,1997), aumento da capacidade de aprendizagem (HINCKLEY, 1985) e melhor tomada de decisão (KANTER, 1983; ZEFFANE, 1996).

Para uma gestão eficaz dos processos se faz necessário a implantação de projetos. Um método muito utilizado para auxiliar na implantação de projetos é o método $5 \mathrm{~W} 1 \mathrm{H}$, que consiste em um documento organizado que identifica as ações e as responsabilidades de quem irá executar, através de um questionamento simples, capaz de orientar as diversas ações que deverão ser implantadas (BAUER, et al. 2002).

$\mathrm{O}$ Método $5 \mathrm{~W} 1 \mathrm{H}$ "deve ser estruturado para permitir uma rápida identificação dos elementos necessários à implantação do projeto". Os elementos, que dão origem a sigla, podem ser descritos como:

\footnotetext{
$\checkmark \quad$ WHAT - O que será feito (etapas)

$\checkmark$ WHY - Por que deve ser executada a tarefa (justificativa)

$\checkmark \quad$ WHERE - Onde cada etapa será executada (local)

$\checkmark \quad$ WHEN - Quando cada uma das tarefas deverá ser executada (tempo)

$\checkmark \quad$ WHO - Quem realizará as tarefas (responsabilidade)
} 
HOW - Como deverá ser realizado cada tarefa/etapa (método)

\section{METODOLOGIA}

O presente estudo busca demonstrar a implantação de modo dinâmico, padronizado e eficaz de ferramentas de Gestão à Vista em uma grande empresa brasileira do setor têxtil.

A pesquisa é caracterizada como aplicada em sua natureza, pois objetiva gerar conhecimentos para aplicação prática dirigidos à solução de problemas específicos (SILVA; MENEZES, 2001). Do ponto de vista de sua abordagem, a pesquisa é considerada como qualitativa, pois a atribuição de significados são básicos sem a utilização de métodos e técnicas estatísticas, sendo o ambiente natural a fonte direta para coleta de dados e o pesquisador é o instrumento-chave para viabilizar o processo (SILVA; MENEZES, 2001).

Considerando os procedimentos técnicos, a pesquisa envolve a pesquisa-ação, pois abriga varias atividades que pretendem promover a mudança no grupo, seja nas organizações, ou nos demais segmentos da sociedade (DICKENS; WATKINS, 1999)

A pesquisa foi realizada em um período de seis meses, entre os meses de Junho e Novembro de 2010, com 36 teares listradores de amostra.

Assim, o estudo encontra-se focado na atividade de supervisão da produção, monitorando o funcionamento dos teares e as atividades pertinentes para que os mesmos mantenham-se abastecidos e por sua vez em pleno funcionamento. No campo de observação são caracterizados a população que engloba a malharia da indústria têxtil específica; a amostra que engloba os teares circulares listradores e as variáveis a serem observadas, sendo estas a produtividade do setor, métodos de solicitação de matéria-prima e tempo de atendimento aos clientes internos.

As ferramentas utilizadas para avaliação, controle e monitoramento do processo foram: escolha de indicadores para medição de desempenho, análise das interações inter-colaboradores através observação in loco e entrevistas abertas, análise dos fatores de atraso através de técnicas como brainstorming, método do 5W1H e o gráfico de Causa-Efeito.

O presente estudo foi desenvolvido em duas frentes paralelamente, uma com foco no Processo de Produção da Malha e a outra no processo de Supervisão da Produção Malharia Circular Listradora. Convicto que em ambas as situações o retorno poderia ser medido pelo indicador de produtividade e para cada frente por indicadores específicos.

Revista de Administração e Inovação, São Paulo, v. 11, n.1, p.162-180, jan./mar. 2014. 
Em cada uma das frentes as atividades foram sequenciadas em quatro etapas básicas: Análise da situação atual, Identificação de problemas, Propostas de melhoria e análise do resultado (Figura 3).

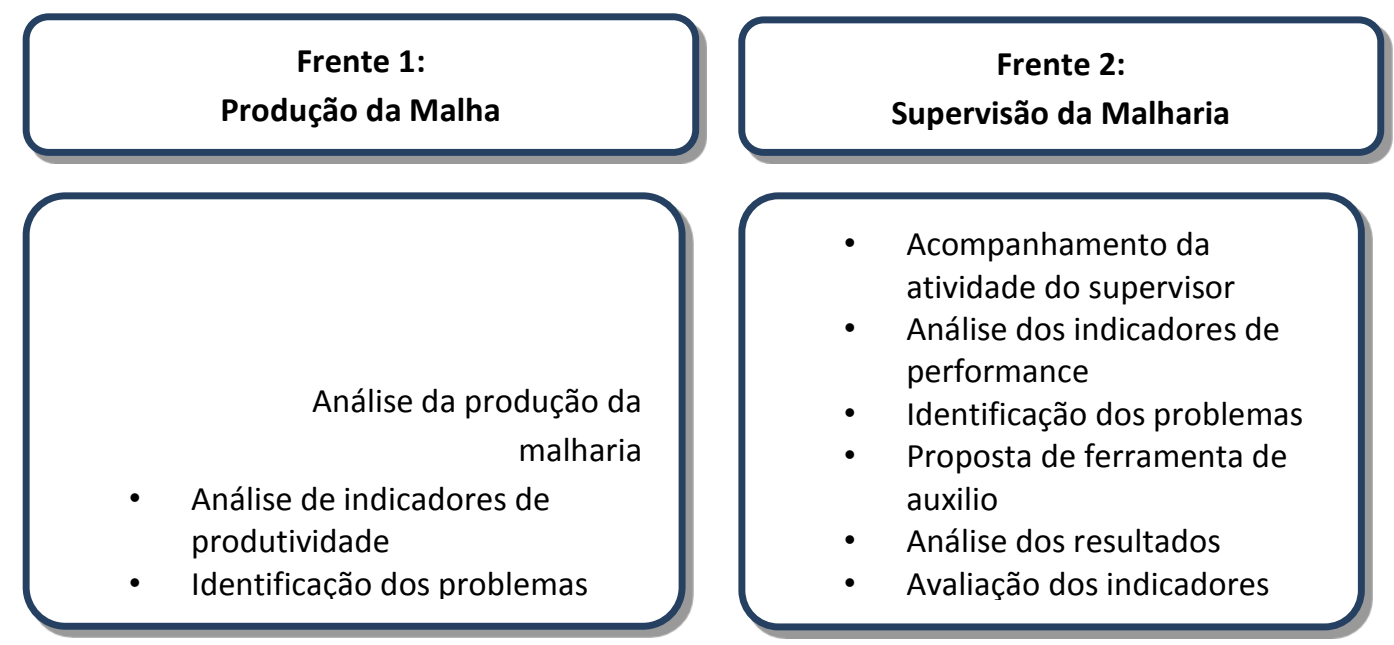

Figura 3 - Esquema das atividades das frentes de trabalho

Fonte: Empresa pesquisada.

\section{Frente 1:}

O pesquisador instalou ao final de cada fileira de quatro máquinas duas bandeiras, como podem ser observadas na Figura 4, uma amarela e a outra vermelha cada uma remetendo aos problemas de Falta de Matéria-Prima e Problemas no tear, respectivamente.
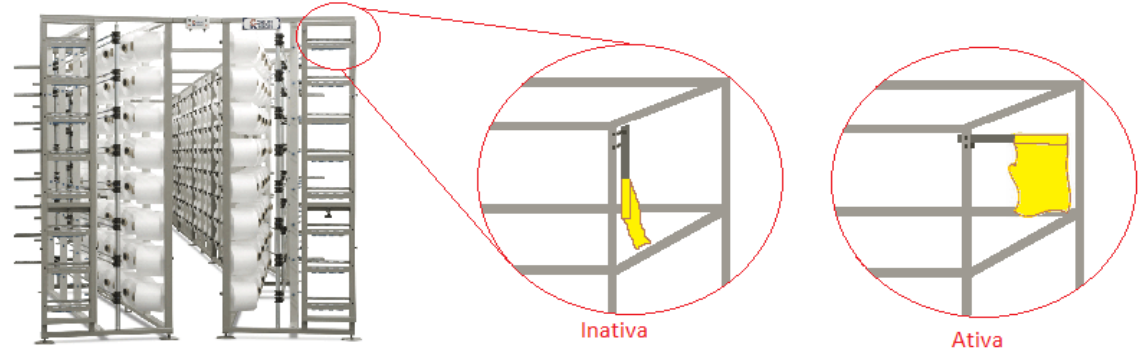

Figura 4 - Projeto de suporte para bandeira

Fonte: Empresa pesquisada.

A vermelha remete a problemas relacionados à manutenção corretiva da máquina, tanto mecânica quanto elétrica, que é um problema mais urgente. O hasteamento da bandeira amarela significa que o fio está para acabar, deste modo o abastecedor de fio terá o tempo necessário para pegar a solicitação e providenciar a matéria prima. Assim o problema de parada de máquinas deixa de ser local e passa a ser geral para todos os membros da equipe da malharia. 
Para ratificar a utilização da ferramenta e esclarecer o papel de cada colaborador no processo, apoiados na técnica de $5 \mathrm{~W} 1 \mathrm{H}$ ficou definido que:

Tabela 1 - Aplicação do 5W1H.

\begin{tabular}{|c|c|c|c|c|c|}
\hline $\begin{array}{l}\text { O que? } \\
\text { (What) }\end{array}$ & $\begin{array}{l}\text { Quando? } \\
\text { (When) }\end{array}$ & $\begin{array}{l}\text { Quem? } \\
\text { (Who) }\end{array}$ & Porque? (Why) & $\begin{array}{l}\text { Onde? } \\
\text { (Where) }\end{array}$ & $\begin{array}{l}\text { Como? } \\
\text { (How) }\end{array}$ \\
\hline $\begin{array}{l}\text { Alertar } \\
\text { previamente } \\
\text { o fim da } \\
\text { Matéria } \\
\text { Prima. }\end{array}$ & $\begin{array}{l}\text { Ao perceber } \\
\text { que falta por } \\
\text { volta de } 1 \\
\text { hora para } \\
\text { acabar a MP. }\end{array}$ & $\begin{array}{l}\mathrm{O} \text { operador de } \\
\text { máquina. }\end{array}$ & $\begin{array}{l}\text { Para eliminar as } \\
\text { paradas de } \\
\text { máquina } \\
\text { desnecessárias. }\end{array}$ & $\begin{array}{l}\text { No ultimo } \\
\text { suporte para } \\
\text { fios(gaiola), } \\
\text { da fileira. }\end{array}$ & $\begin{array}{l}\text { Hasteando a } \\
\text { bandeira } \\
\text { amarela. }\end{array}$ \\
\hline
\end{tabular}

\section{Fonte: Empresa pesquisada}

\section{Frente 2:}

A frente 2 busca automatizar o processo que foi implementado na frente 1, pois para Machado e Moraes (2011) o uso de tecnologia da informação trazem aumento da produtividade, velocidade, confiabilidade, redução de tempos e custos produtivos.

Para este problema a ferramenta proposta será baseada totalmente na Gestão à Vista, onde será utilizado um computador como Painel informativo em tempo real, onde todos os teares estariam ligados a esta central, passando informações básicas, como status (ligado ou desligado), número de voltas do tear, velocidade de operação. De acordo com o modelo na Figura 5.

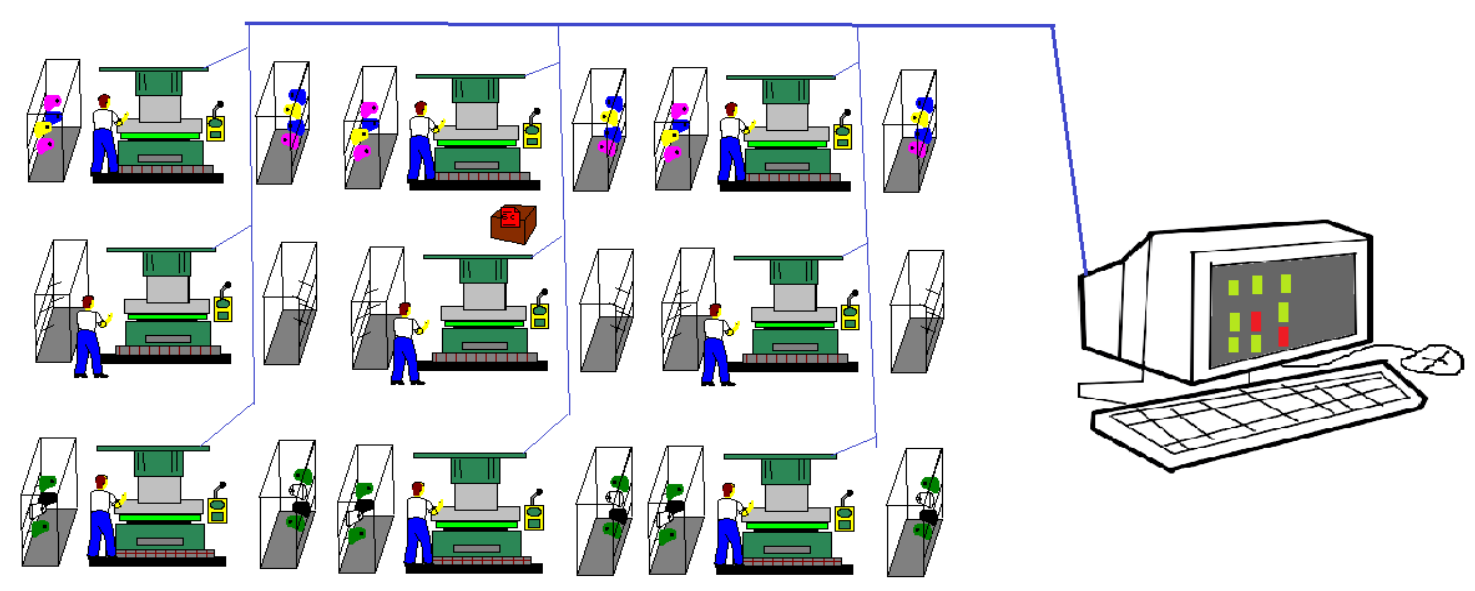

Figura 51 - Esquema de interligação dos teares a uma central

Fonte: Empresa pesquisada 
Em posse de um uma central única para consulta, em tempo real, de todos os teares, o Supervisor poderá rapidamente verificar o status de todos os teares e prestar atenção especial nos que estão parados há mais tempo e dirigir-se diretamente ao foco do problema.

\section{ESTUDO DE CASO: INDÚSTRIA BRASILEIRA DO SETOR TÊXTIL}

A indústria analisada pertence ao maior grupo empresarial de moda do Brasil e controlador de mais de 150 lojas varejistas em todo o território nacional. Essa indústria atua desde a produção têxtil até a confecção, entretanto o trabalho foi realizado em uma das etapas da produção têxtil, que é a malharia.

Atualmente a organização tem dois centros de manufatura, tendo o trabalho sido desenvolvido apenas na divisão alocada no estado do Rio Grande do Norte, os quais excedem a produção diária de 300.000 itens. A planta avaliada é responsável pela produção das malhas e linhas de roupas, com uma área total de $150.000 \mathrm{~m}^{2}$.

No ano de 2010, a produção cresceu 3,0\%, passando de 51,8 milhões de peças em 2009 para 53,3 milhões em 2010. Este comportamento é resultado da produção de itens de maior valor agregado e da adequação da produção à necessidade das suas lojas de varejos, visto seu atual ritmo de expansão.

O grupo empresarial tem como Missão proporcionar, a cada vez mais pessoas, as condições de se expressar através da moda e visa liderar o mercado nacional de moda, em um predominantemente formal.

\section{ANALISE E DISCUSSÃO DOS RESULTADOS}

\section{Frente 1}

Após um período substancialmente significante para análise dos indicadores da situação atual. Foram levantados os seguintes dados para que fosse realizada uma análise prévia dos indicadores.

A Figura 6 demonstra o histórico de 15 dias do abastecimento das máquinas em antes da implementação do projeto. 


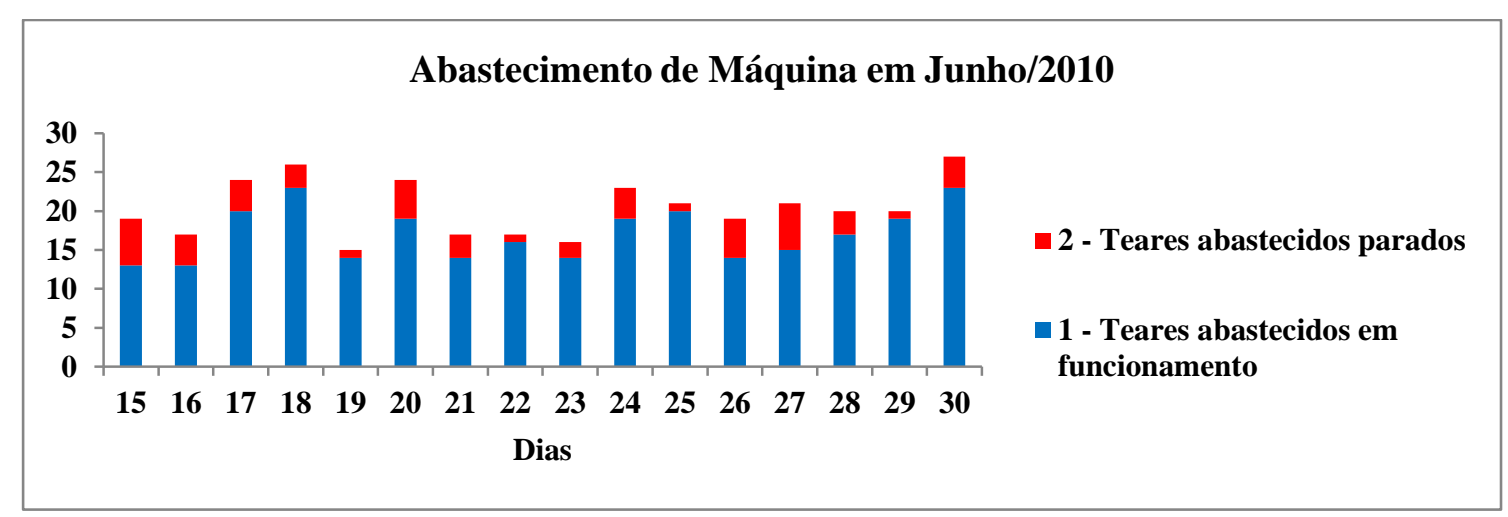

Figura 6 - Abastecimento de máquina

Fonte: Empresa pesquisada

Por intermédio da Figura 6 percebe-se maquinas paradas devido à espera por abastecimento de matéria prima em todos os dias analisados, gerando perda de tempo operacional e consequentemente perda de eficiência.

O principal problema das paradas estava relacionado com a falta de comunicação entre o operador do tear e o abastecedor de fios. Para solucionar este problema foi proposta uma ferramenta baseada nos princípios do Kanban, como puxar a produção (alertando à hora de execução da atividade imediatamente anterior) e também de se antecipar ao problema, informando ao abastecedor de fios, em tempo hábil, que não há a quantidade suficiente para concluir o produto, ou já antecipar os fios do próximo produto que será trocado, caracterizando assim um pré-setup, diminuindo o tempo de máquina parada por falta de fio.

Por intermédio das Figuras 7 e 8 pode-se observar o mecanismo implementado na frente 1.

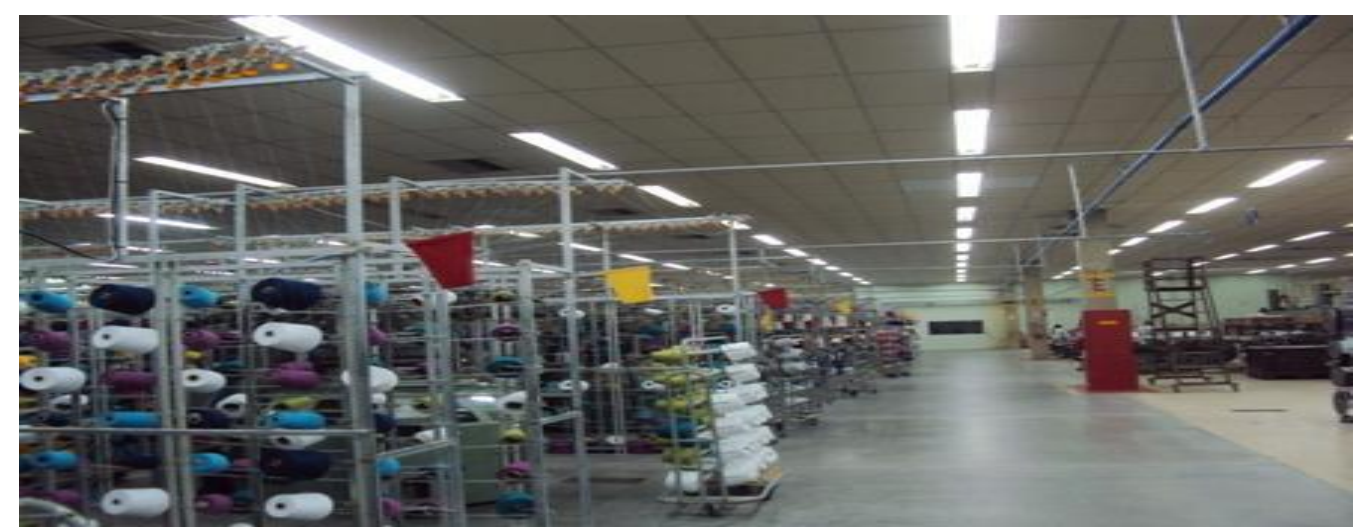

Figura 7 - Visualização panorâmica das bandeiras

Fonte: Empresa pesquisada 


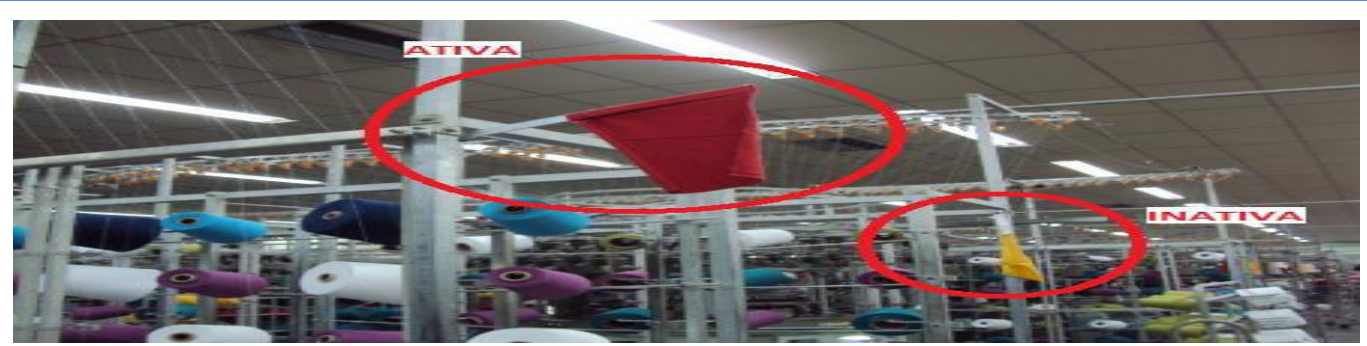

Figura 8 - Visão aproximada das bandeiras

Fonte: Empresa pesquisada

Percebe-se por intermédio da figura 7 o hasteamento de uma bandeira gera fácil visualização, tanto do abastecedor como do responsável pelo gerenciamento do processo.

Em apenas 15 dias após a implantação o indicador 2, Teares abastecidos parados, diminuiu consideravelmente, margeando o índice zero. Como demonstrado na Figura 9.

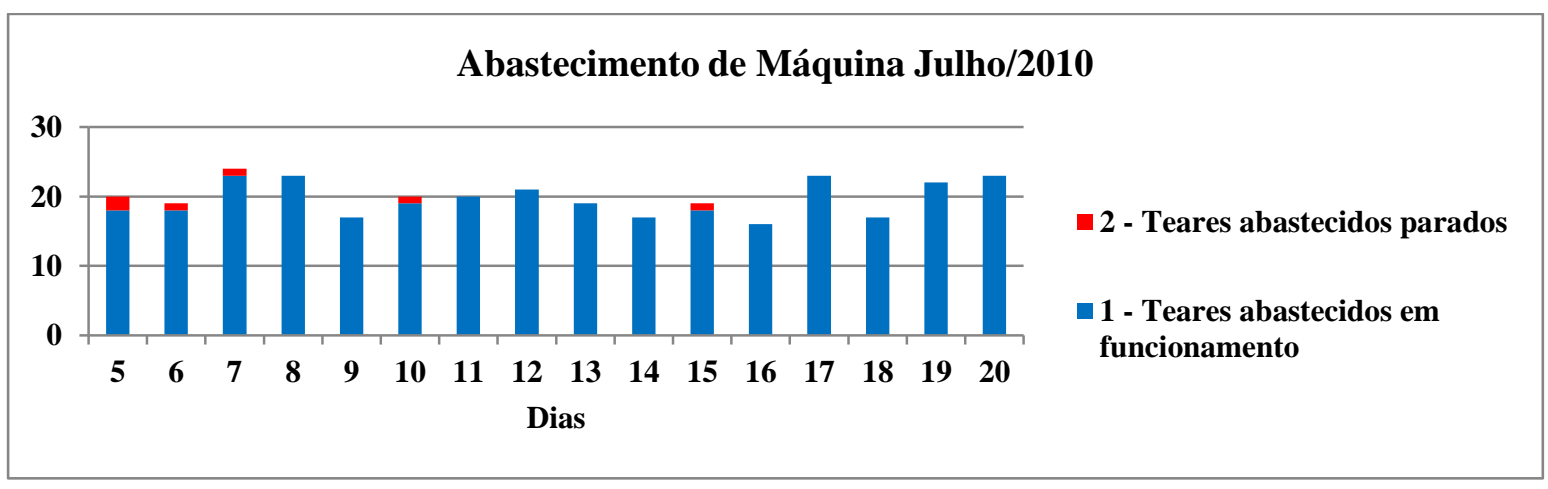

Figura 9 - Abastecimento de Máquina em Julho/2010

Fonte: Empresa pesquisada

Os dados iniciais provam que, além da simplicidade e funcionalidade da ferramenta, o simples fato de padronizar e oficializar um processo, deixando claro para todos a sua função, problemas rotineiros podem ser eliminados, sem grandes mudanças.

Em agosto, seguindo a tendência houve mais uma queda, e finalmente em setembro atingiu-se a marca histórica de nenhum erro no recebimento pontual de matéria prima, como pode ser observado na Figura 10. 


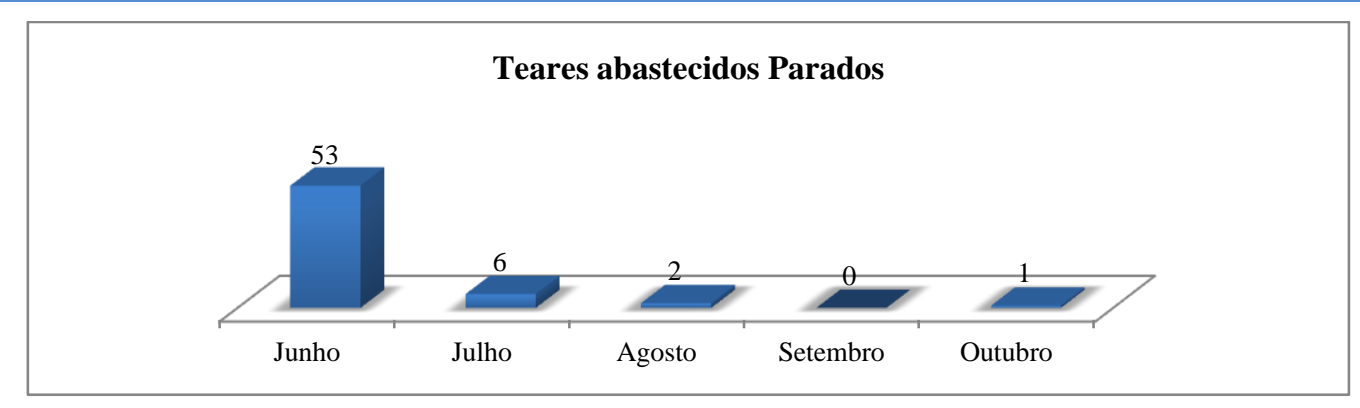

Figura 10 - Teares abastecidos parados

Fonte: Empresa pesquisada

\section{Frente 2}

A frente 2 tinha o objetivo automatizar o processo de gestão a vista implementados na frente 1 . Uma televisão foi instalada na linha de produção em local visível para todos trazendo informações de cada tear. (Figura 11).

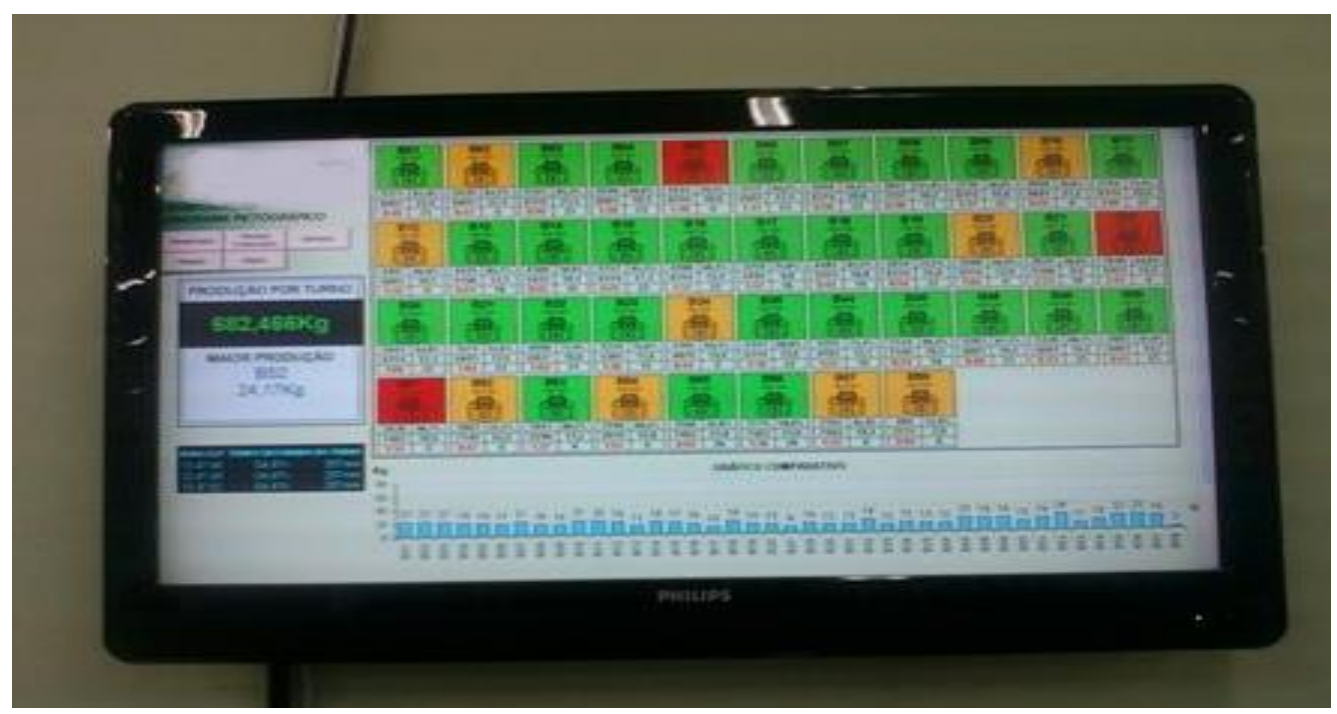

Figura 112 - Totem funcionando

Fonte: Empresa pesquisada

Nessa Figura 11, observa-se, em cada ícone representa um tear com suas respectivas informações, sendo essas informações descritas na Figura 12.

No totem demonstrado na Figura 11, percebe-se ao lado direito uma estimativa da produção diária para verificar se será possível cumprir metas e abaixo na mesma figura verifica-se produtividade de cada máquina. 


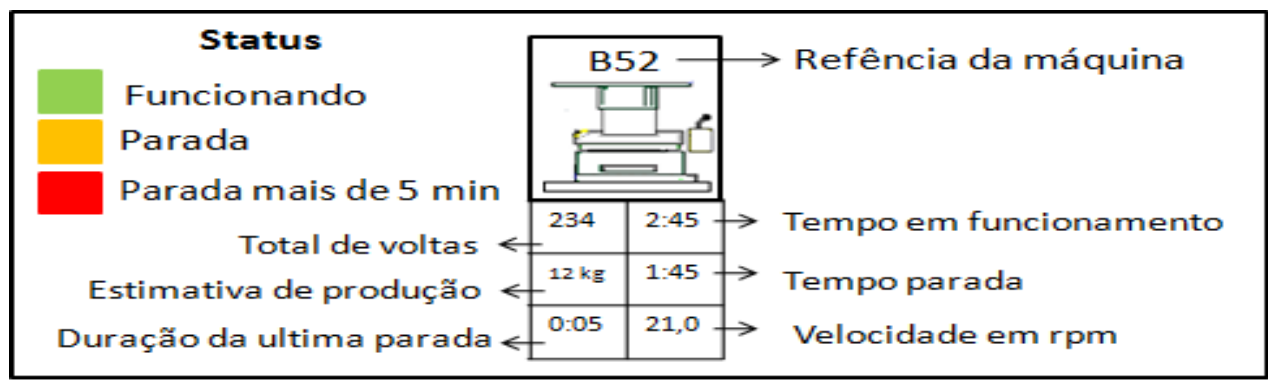

Figura 12 - Legenda do Totem

Fonte: Empresa pesquisada

A utilização da gestão visual ficou evidenciada na figura 12, pois com uma velocidade pode-se verificar se existem máquinas paradas e caso positivo, há quanto tempo estas estão nesta situação.

Por sugestão dos supervisores, foi adicionado também o campo de velocidade, o que mitigou a possibilidade do operador reajustar a velocidade por conta própria, sem comunicar o supervisor algum motivo factível para ser analisado.

Posteriormente, aproveitando que a empresa possui um sistema de intranet, foi pensado em colocar a mesma tela na opção pertinente a malharia. Uma vez que ficaria disponível para o acesso do Gerente, diretor-industrial e demais interessados, de sua própria sala, ou até de casa em ocasiões especiais, e aproveitando que os supervisores têm folga dominical. Sem necessitar de um grande esforço para adaptar ao sistema.

Em relação aos indicadores de supervisão, antes da avaliação quantitativa, não houve nem dúvida em relação à opinião dos supervisores e gerente, foi unanimidade a satisfação proporcionada pela ferramenta, principalmente pela mudança na rotina da supervisão que conseguiu diminuir o número de rondas na linha de produção.

O supervisor passou a realizar rondas para aumentar a interação com seus subordinados, coletar opiniões, auxiliar em outros problemas, diminuindo o tempo destinado a gestão da produção e aumentando o tempo relacionado à gestão de pessoas e novos projetos. 


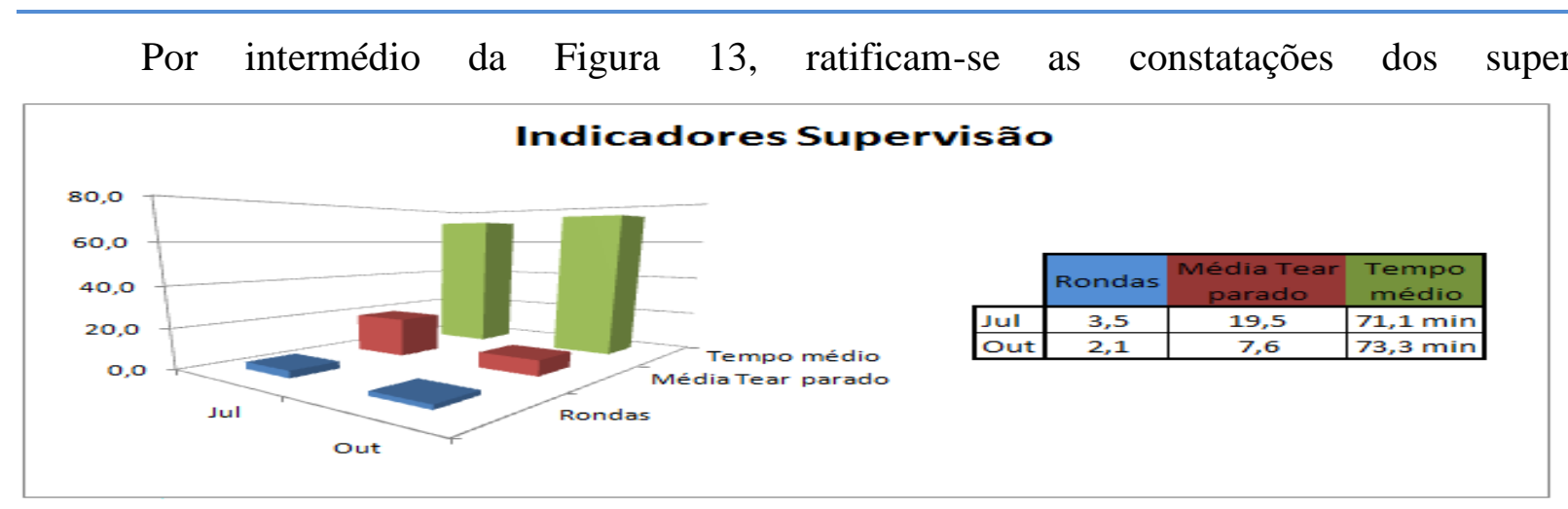

Figura 13 - Comparativo entre os indicadores da supervisão

Fonte: Empresa pesquisada

A Figura 13 demonstra a redução de $40 \%$ no número de rondas efetuadas pelos supervisores na linha de produção, redução de $61 \%$ no tempo médio das máquinas paradas e aumento de $3 \%$ no tempo médio das rondas, justificado pela maior interação do supervisor com os operadores.

A implementação das ferramentas de gestão a vista desenvolvidas neste estudo trouxe como consequência aumento na produtividade da planta fabril estudada (Figura 14).

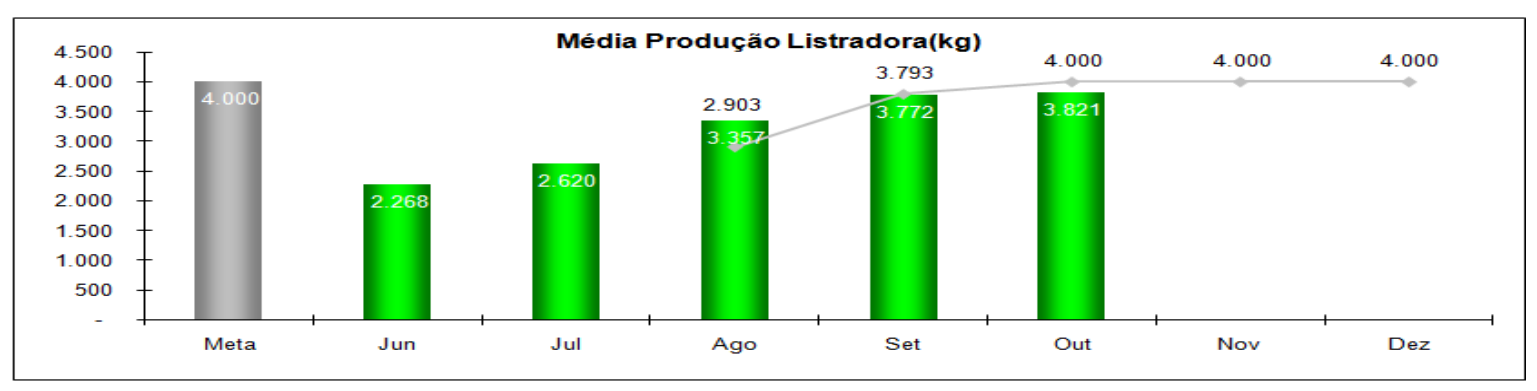

Figura 14: Média de Produção diária no ano de 2010.

Fonte: Empresa pesquisada

Por intermédio da Figura 14 podemos perceber grandes acréscimos na produtividade das máquinas a partir do mês de Junho, onde foram instaladas as ferramentas de gestão à vista. Logo no primeiro mês após a implementação houve um acréscimo de $15 \%$ em relação ao mês de Junho. Esse aumento foi ainda maior se comparado com os meses de Agosto (48\%), Setembro (66\%) e Outubro $(68 \%)$.

Esses acréscimos na produtividade das máquinas foram decisivos para auxiliar a planta fabril atingir sua meta de produção estipulada pela companhia. 


\section{CONSIDERAÇÕES FINAIS}

No mercado globalizado, ser competitivo é fator crucial, sendo necessária a busca por inovações e novos conhecimentos.

As ferramentas da gestão à vista neste estudo mostrou-se ser uma inovação em seu processo de produção, trazendo diversos benefícios, tais como padronização do processo, maior conscientização dos colaboradores e aumento da produtividade.

Com o hasteamento das bandeiras, a informação de que havia uma máquina parada esta sendo melhor distribuída, facilitando a comunicação entre os colaboradores em prol da uma solução rápida.

Percebe-se que após quatro meses da implementação das ferramentas de gestão à vista foi possível notificar a redução de $40 \%$ no número de rondas efetuadas pelos supervisores na linha de produção, disponibilizando o tempo desses profissionais para gestão de pessoas e de novos projetos. Percebe-se também redução de $61 \%$ no tempo médio das máquinas paradas, possibilitando um acréscimo de $68 \%$ na produtividade na linha dos teares, contribuindo substancialmente para que a unidade atingisse a meta de produção anual.

Como limitação do estudo não foi mapeado o histórico de problemas elétricos e mecânicos que ocorreram durante o estudo com o hasteamento da bandeira vermelha, porem é fato que a comunicação entre os setores de produção e manutenção foi facilitado.

\section{REFERÊNCIAS}

AGHAJANI, M, KERAMATI, A; JAVADI, B. Determination of number of kanban in a cellular manufacturing system with considering rework process. International Journal of Advanced Manufacturing Technology. V. 63, n. 9-12, pp 1177-1189, 2012.

BAUER, J.E.; DUFFY, G.L.; WESTCOTT, R.T. The quality improvement handbook. EUA. ASQ, 2002.

BATEMAN, T. S., SNELL, S. A. Administração: construindo vantagem competitiva. São Paulo: Atlas, 1998.

BRAVO, I. Gestão de qualidade em tempos de mudanças. Campinas, Alínea, 2003.

CHEE, S. L.;CHONG, M.Y.; CHIN, J.F. Milk-run kanban system for raw printed circuit board withdrawal to surface-mounted equipment. Journal of Industrial Engineering and Management. V.5, n.2, pp 382-405, 2012.

CHIAVENATO, I. Administração nos novos tempos. 2 ed. Rio de Janeiro: Campus, 1999.

Revista de Administração e Inovação, São Paulo, v. 11, n.1, p. 162-180, jan./mar. 2014. 
COLENGHI, V.M. O\&M e qualidade total: uma interpretação perfeita. 3 ed. Uberaba: V.M., 2003. CORREAA, H. L.; GIANESI, I. G. N.; CAON, M. Planejamento, programação e controle da produção: MRP II, ERP: conceitos, uso e implantação. São Paulo: Atlas, 2007.

DAVENPORT, T. H.;L. PRUSAK. Conhecimento empresarial: como as organizações gerenciam o seu capital intelectual. Rio de Janeiro: Campus. 1998.

DICKENS, L.; WATKINS, K. Action research: rethinking Lewin. Management Learning, 30, 2, 127 140, 1999.

FURUKAWA, T.; HONG, S.C. The determination of the optimal number of kanbans in a JIT production system. Comput Ind Eng. V. 24, n.4, pp 551-559, 1993.

GWIAZDA, A. Quality tools in a process of technical project management. Journal of Achievements in Materials and Manufacturing Engineering. V.18, n.1-2, 2006.

HINCKLEY, S.R. A closer look at participation. Organizational Dynamics, Vol. 13 No. 3, pp. 57-67, 1985.

KANTER, R.M. The change masters. Simon \& Schuster, New York, NY, 1983.

KIERNAN, M.J. The new strategic architecture: learning to compete in the twenty-first_Century. Academy of Management Executive, V. 7 n. 1, pp. 7-21, 1993.

LAUDON, K. C.; LAUDON, J. P. Sistemas de informação com Internet. $4^{\text {a }}$ Edição, São Paulo, Editora JC, 2004

LAWLER, E.E. The ultimate advantage. Jossey Bass Publishers, San Francisco, CA, 1993.

MACHADO, A.G.C; MORAES, W.F.A. Tecnologia de informação e customização em massa: evidências na indústria de transformação. Revista de Administração e Inovação, São Paulo, v. 8, n. 2, p.190-215, 2011.

MELLO, C. H. P. (1998) - Auditoria continua: estudo de implementação de uma ferramenta de monitoramento para sistema de garantia da qualidade com base nas normas NBR ISO9000. Dissertação de Mestrado, Itajubá: EFEI, 1998.

PARDO-DEL-VAL, M. et al. Participative management and its influence on organizational change. Management Decision. V. 50, n.10, pp 1843-1860, 2012.

PINTO, S. H. B., Carvalho, M. M. D.; Ho, L. L. Implementação de programas de qualidade: um survey em empresas de grande porte no Brasil. Gestão \& Produção, 13, 191-203, 2006.

QUINN, R.E.; SPREITZER, G.M. The road to empowerment: seven questions every leader should consider. Organizational Dynamics, V. 26, n. 2, pp. 37-49, 1997.

RANGEL, A.S; SILVA, M.M.; COSTA, B.K. Competitividade da indústria têxtil brasileira. Revista de Administração e Inovação, São Paulo, v. 7, n. 1, p. 151-174, 2010.

ROSSETTI, E.K, et al. Sistema Just in Time: Conceitos imprescindíveis. Revista Qualit@s. V. 7,n.2, 2008. 
RODRIGUES, M.V.C. Ações para a qualidade: GEIQ, gestão integrada para a qualidade: padrão seis sigma. Classe mundial. Rio de Janeiro: Qualitymark, 2004.

SCAVARDA, A.J. A. Methodology for constructing collective causal maps. Decision Sciences V. 37 n. 2, 2006.

SCHONBERGER, R.J. e KNOD JR, E.M. Operations management. 5 ed. Illinois: IRWIN, 1994.

SHINGO, S. A. Revolution in Manufacturing. Cambridge: Productivity Press, 1985.

SILVA, E.L; MENEZES, E.M. Metodologia da pesquisa e elaboração de dissertação. 3. ed. rev. atual. - Florianópolis: Laboratório de Ensino a Distância da UFSC,2001.

SLACK, N. Vantagem competitiva em manufatura. Atlas, São Paulo, 1993.

SLACK, N.; et. al. Administração da Produção. 2. ed. São Paulo: Atlas, 2007.

TONKIN, L. A. P. Effective Visual Management: bring excellence into shaper focus. LTC, Rio Janeiro, 1998.

TUBINO, D. F. Manual de planejamento e controle da produção. 2. ed, São Paulo, Editora Saraiva, 2000.

ZEFFANE, R. Dynamics of strategic change: critical issues in fostering positive organizational change. Leadership \& Organization Development Journal, V. 17, n. 7, pp. 36-43, 1996. 


\title{
ASSESSMENT AND MONITORING OF PRODUCTION PROCESSES USING RESOURCES MANAGEMENT IN SIGHT IN A BIG TEXTILE INDUSTRY OF RIO GRANDE DO NORTE - BRAZIL
}

\begin{abstract}
Competition industry increasingly requires companies that need new alternatives in order to remain competitive in the market. Management tools help in sight communications, providing agility in solving problems bringing benefits to companies. The present study aims to demonstrate the deployment of a dynamic, standardized and effective visible management tools in order to enhance the effectiveness of the spread of information in a plant of the largest industries of the Brazilian textile sector, aiming to make the company more competitive in the global market. This type of research is exploratory, descriptive and evaluative, with the mode of action research investigation. The Data were collected through unstructured interviews, document analysis and observation. After four months of implementation of management tools to view, we noticed a $40 \%$ reduction in the number of number of patrols made by supervisors on production lines, $61 \%$ reduction in the time machine downtime and increase of $68 \%$ in daily productivity. Another important result of the study showed improvement in communication between employees, less failure in the process of production and better monitoring by management.
\end{abstract}

Data do recebimento do artigo: 14/07/2013

Data do aceite de publicação: 25/11/2013

Revista de Administração e Inovação, São Paulo, v. 11, n.1, p.162-180, jan./mar. 2014. 